\title{
NOTA
}

\section{ESTRESSE SALINO NO CRESCIMENTO INICIAL E NUTRIÇÃO MINERAL DE GLIRICÍDIA (Gliricidia sepium (Jacq.) Kunth ex Steud) EM SOLUÇÃO NUTRITIVA ${ }^{(1)}$}

\author{
Séfora Gil Gomes de Farias ${ }^{(2)}$, Diércules Rodrigues dos Santos ${ }^{(3)}$, Antonio \\ Lucineudo de Oliveira Freire ${ }^{(4)} \&$ Romário Bezerra e Silva ${ }^{(5)}$
}

\begin{abstract}
RESUMO
A salinidade é um dos fatores que mais limitam o crescimento e desenvolvimento de plantas na região semiárida. A sobrevivência destas em ambientes salinos dependerá de processos adaptativos, que envolvem absorção, transporte e distribuição de íons nos vários órgãos da planta. Com o objetivo de avaliar o crescimento e a nutrição mineral de mudas de gliricídia cultivada em diferentes condições de salinidade, realizou-se um experimento em telado de náilon da Unidade Acadêmica de Engenharia Florestal da Universidade Federal de Campina Grande, Patos - PB. As sementes foram colocadas para germinar em vasos de Leonard, contendo solução nutritiva de Hoagland \& Arnon (50 \% da concentração original), com as concentrações de $\mathrm{NaCl}$ : 0,100200 e $400 \mathrm{mmol} \mathrm{L}^{-1}$. Os tratamentos foram distribuídos em delineamento inteiramente casualizado, com quatro repetições, com uma planta por vaso. Aos 60 dias após a emergência, as plantas foram colhidas e avaliadas quanto a altura, matéria seca e teores de $\mathrm{N}, \mathrm{P}$, $\mathrm{K}, \mathrm{Ca}, \mathrm{Mg}$, S e Na na raiz, no caule e nas folhas. $\mathrm{O}$ aumento da salinidade promoveu reduções no crescimento e nos teores de macronutrientes, ocorrendo o inverso nos teores de Na, sobretudo na raiz. A gliricídia mostrou-se sensível à salinidade.
\end{abstract}

Termos de indexação: salinidade, nutrientes, semiárido.

\footnotetext{
(1) Parte da Dissertação de Mestrado do primeiro autor, apresentada à Universidade Federal de Campina Grande - UFCG. Recebido para publicação em outubro de 2008 e aprovado em junho de 2009.

(2) Mestre em Zootecnia pela Universidade Federal de Campina Grande - UFCG, Centro de Saúde e Tecnologia Rural - CSTR. Campus de Patos, Caixa Postal 64, CEP 58700-970 Patos (PB). E-mail: sefora@gmail.com

(3) Professor Adjunto da Unidade Acadêmica de Engenharia Florestal, UAEF/UFCG. E-mail: santos@cstr.ufcg.edu.br

(4) Professor Associado da UAEF/UFCG. E-mail: lofreire@cstr.ufcg.edu.br

${ }^{(5)}$ Graduando em Engenharia Florestal da UFCG. E-mail: romariobs@gmail.com
} 


\title{
SUMMARY: GROWTH AND MINERAL NUTRITION OF (Gliricidia sepium (Jacq.) Kunth ex Steud) SEEDLINGS IN NUTRIENT SOLUTION UNDER SALINE STRESS
}

\begin{abstract}
Salinity is one of the most limiting factors to plant growth and development. Plant survival in saline environments depends on adaptive processes involving uptake, transport, and distribution of ions in plant organs. To evaluate growth and mineral nutrition of Gliricidia sepium seedlings under saline conditions, an experiment was carried out under nylon-mesh protection, at the Federal University of Campina Grande, in Patos - PB. Seeds were sown in pots containing Hoagland \& Arnon nutrient solution with four $\mathrm{NaCl}$ levels (0, 100, 200 and $400 \mathrm{mmol} \mathrm{L}^{-1}$ ), with four replications (1 plant/pot) in a completely randomized design. Sixty days after seedling emergence, the plant height and root, stem and leaf dry matter, and nutrient (N, $P, K, C a, M g, S$ and $N a)$ accumulation were measured in the plant tissues. All variables but Na were negatively affected by increasing $\mathrm{NaCl}$ levels in the nutrient solution, particularly in the root tissue. Results indicated the sensitivity of Gliricidia sepium to salinity.
\end{abstract}

Index terms: salinity, nutrients, semiarid.

\section{INTRODUÇÃO}

A salinidade é um dos fatores que mais limitam o crescimento e a nutrição mineral de plantas em regiões com baixa disponibilidade hídrica, devido à redução do potencial osmótico no ambiente radicular (Dasgan et al., 2002). A alta concentração de sais é considerada um fator estressante para as plantas, por apresentar atividade osmótica, retendo a água, além da ação de íons sobre o protoplasma e do impacto sobre a nutrição mineral das plantas (Chusman, 2001; Munns, 2002).

A salinidade altera a nutrição mineral das culturas, reduzindo a atividade dos íons em solução e alterando os processos de absorção, transporte, assimilação e distribuição de nutrientes na planta. A interação entre salinidade e nutrição mineral tornase mais complexa em virtude das diferenças na concentração e na composição iônica dos meios salinos (água e solo) aos quais as plantas são submetidas, bem como das diferentes respostas das plantas, tanto em relação à salinidade como no tocante à eficiência na aquisição de nutrientes do solo. É possível sugerir, no entanto, que a predominância de determinados elementos minerais no ambiente radicular, como é comum em meios salinos, altera direta ou indiretamente a aquisição de nutrientes, podendo acarretar redução no crescimento e alterações na qualidade do produto vegetal (González-Fernández \& Cuartero, 1993; Lacerda, 2005).

A inibição do crescimento das plantas pelo estresse salino pode ser consequência de efeitos osmóticos, provocando déficit hídrico e, ou, de efeitos específicos de íons, que podem acarretar toxidez ou desequilíbrio nutricional (Munns, 2002). Entretanto, o grau com que cada um desses componentes do estresse salino influencia o crescimento é dependente de muitos fatores, como espécie vegetal, cultivar, tipo de salinidade, intensidade e duração do estresse salino, luminosidade, umidade do solo e do ar e estádio de desenvolvimento da planta (Cramer et al., 1994).

A resposta das plantas à salinidade é um fenômeno complexo, envolvendo alterações morfológicas e de crescimento, além de processos físiológicos e bioquímicos (Fougère et al., 1991). Essas plantas têm a capacidade de estabelecer um equilíbrio osmótico com a baixa disponibilidade de água no solo (Lima, 1997). As diferenças são grandes entre as espécies de plantas na habilidade para prevenir ou tolerar elevadas concentrações de Na nas folhas (Fernandes et al., 2002).

Assim, a sobrevivência em ambientes salinos pode resultar de processos adaptativos que envolvem absorção, transporte e distribuição de íons nos vários órgãos da planta e sua compartimentalização dentro das células (Munns \& Termaat, 1986). Os íons inorgânicos desempenham importante papel na preservação do potencial hídrico vegetal; portanto, mecanismos em plantas que levam ao excesso de absorção iônica e exclusão de $\mathrm{Na}^{+} \mathrm{e} \mathrm{Cl}^{-}$de tecidos metabolicamente ativos da parte aérea podem ser responsáveis pela tolerância das culturas ao estresse salino (Greenway \& Munns, 1980). Essa exclusão pode ser efetuada pela acumulação preferencial de íons em tecidos relativamente tolerantes da raiz ou da parte aérea (Boursier et al., 1987).

Segundo observações de Tyerman \& Skerrett (1999), em ambientes salinos, o $\mathrm{NaCl}$ tem-se mostrado o sal predominante, causando a maioria das injúrias nas plantas. Outros trabalhos ratificaram o efeito negativo do $\mathrm{NaCl}$ no crescimento vegetal (Silva et al., 2000; Neves et al., 2004).

O efeito osmótico tem sido a causa maior da redução do crescimento das plantas, associado à toxidez de íons pela absorção excessiva de $\mathrm{Na}$ e $\mathrm{Cl}$ e ao desequilíbrio nutricional causado pelos distúrbios na absorção e, ou, distribuição dos nutrientes. A redução na absorção de $\mathrm{Ca}$, por exemplo, pode levar à perda da integridade 
da membrana plasmática, com consequente perda da capacidade de absorção de alguns íons, principalmente o K (Cachorro et al., 1994; Miranda et al., 2002).

A extensão de terras alteradas por sais no Brasil é estimada em quatro milhões de hectares (Szabolcs, 1989), as quais apresentam baixa produtividade agrícola ou, mesmo, encontram-se fora do sistema produtivo. As atividades silvipastoris poderiam possibilitar a utilização dessas áreas e, certamente, ter reflexos diretos sobre a oferta de produtos de origem arbórea na região Nordeste e na redução da pressão sobre a vegetação nativa, além de promoverem a recuperação dos solos degradados pela salinidade. Contudo, o sucesso dessa iniciativa é dependente, entre outros fatores, da produção de mudas capazes de resistir às condições adversas do meio (Barbosa, 1994).

A gliricídia (Gliricidia sepium (Jacq.) Kunth ex Steud) é uma leguminosa arbórea que apresenta crescimento rápido e enraizamento profundo, o que lhe confere tolerância à seca. Igualmente, suporta a realização de cortes periódicos, como consequência da sua alta capacidade de rebrota. É considerada uma espécie de múltiplos usos, como: adubação verde, forragem, reflorestamento, cerca viva, entre outros (Carvalho Filho et al., 1997).

O objetivo do presente trabalho foi avaliar o crescimento inicial e a nutrição mineral de gliricídia em solução nutritiva submetida a concentrações crescentes de $\mathrm{NaCl}$.

\section{MATERIAL E MÉTODOS}

O experimento foi realizado em ambiente protegido com tela de náilon na Unidade Acadêmica de Engenharia Florestal da Universidade Federal de Campina Grande, campus de Patos (PB), no período de dezembro de 2007 a março de 2008. Utilizou-se, como suporte para as plantas, areia grossa lavada e esterilizada por meio de autoclavagem durante $30 \mathrm{~min}$ $\left(120^{\circ} \mathrm{C} ; 1,0 \mathrm{~atm}\right)$. A areia foi mantida em bacias de plástico contendo solução de $\mathrm{HCl}\left(50 \mathrm{~mL} \mathrm{~L}^{-1}\right)$ por aproximadamente $12 \mathrm{~h}$ e depois lavada em água corrente até completa eliminação do $\mathrm{Cl}^{-}$. Após a lavagem, a areia foi submetida à secagem ao ar e posteriormente acondicionada em vasos de Leonard com capacidade para $600 \mathrm{~mL}$. Os vasos foram montados, utilizando-se $600 \mathrm{dm}^{3}$ da areia lavada na parte superior e solução nutritiva na parte inferior, de acordo com Vincent (1970).

Utilizou-se solução nutritiva de Hoagland \& Arnon (1950) (diluída para meia força iônica), sendo as soluções trocadas a cada cinco dias.

Sementes de gliricídia pré-hidratadas durante uma hora foram colocadas para germinar diretamente nos vasos de Leonard (três sementes por vaso). Aos cinco dias após a emergência, foi realizado desbaste, permanecendo a planta mais vigorosa.
Os tratamentos constituíram-se da adição de três concentrações de $\mathrm{NaCl}$ e mais uma testemunha sem o sal $\left(0,100,200\right.$ e $400 \mathrm{mmol} \mathrm{L}^{-1}$ de $\left.\mathrm{NaCl}\right)$. Para simular a adição gradativa do sal, as concentrações de $\mathrm{NaCl}$ foram adicionadas após o desbaste, aplicandose $100 \mathrm{mmol} \mathrm{L}^{-1}$ de $\mathrm{NaCl}$ diariamente na solução nutritiva, até atingir as concentrações desejadas.

$\mathrm{O}$ delineamento experimental foi inteiramente casualizado, com quatro repetições. Aos 60 dias após a emergência (DAE), avaliou-se a altura das plantas. Em seguida, as plantas foram coletadas, separadas em folhas, caule e raízes e acondicionadas em sacos de papel para secagem em estufa de circulação forçada de ar, com temperatura entre 65 e $70{ }^{\circ} \mathrm{C}$.

Após a secagem, as folhas, os caules e as raízes foram pesados separadamente, para determinação das massas do material seco. Em seguida, folhas e raízes foram moídas e submetidas à digestão nítricoperclórica e avaliadas quanto aos teores de $\mathrm{P}, \mathrm{K}, \mathrm{Ca}$, $\mathrm{Mg}, \mathrm{S}$ e $\mathrm{Na}$, sendo os de $\mathrm{P}$ obtidos por colorimetria; $\mathrm{Ca}$ e Mg, por espectrofotometria de absorção atômica; $\mathrm{K}$ e Na, por fotometria de chama de emissão; e S, por turbidimetria do $\mathrm{BaSO}_{4}$ (Malavolta et al., 1997). Os teores de $\mathrm{N}$ foram determinados no extrato da digestão sulfúrica pelo método semimicro Kjeldahl (Liao, 1981), sendo a destilação e a titulação realizadas de acordo com Bremner \& Edwards (1965).

Os resultados foram submetidos às análises de variância e estudo de regressão simples e ajustados em função dos tratamentos aplicados, utilizando-se o programa estatístico SISVAR (Ferreira, 2000).

\section{RESULTADOS E DISCUSSÃO}

As concentrações crescentes de $\mathrm{NaCl}$ na solução reduziram a altura das plantas em relação à testemunha, seguindo um modelo quadrático (Figura 1).

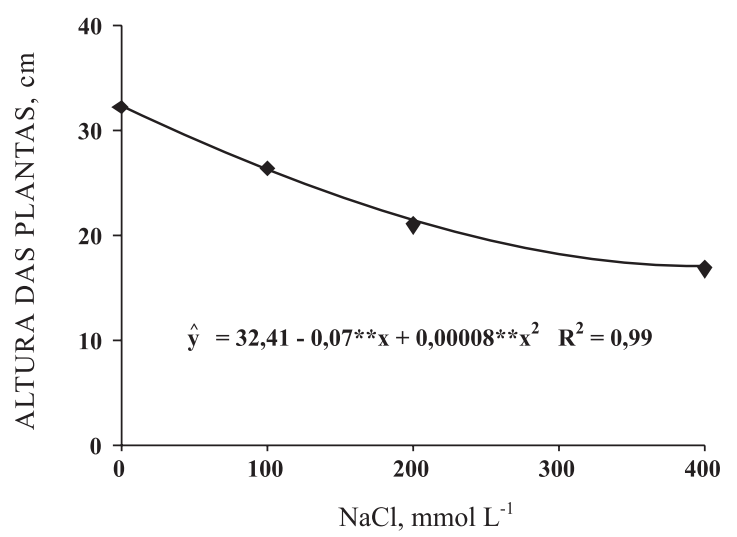

Figura 1. Altura de mudas de gliricídia em função das concentrações crescentes de $\mathrm{NaCl}$ na solução nutritiva. 
As plantas submetidas ao tratamento sem $\mathrm{NaCl}$ alcançaram crescimento máximo de $32,25 \mathrm{~cm}$ durante o período experimental, havendo redução gradativa, que atingiu cerca de $50 \%$ quando se adicionaram $400 \mathrm{mmol} \mathrm{L}^{-1}$ de NaCl. Neves et al. (2004) trataram mudas de umbuzeiro com $0,20,40,60,80$ e $100 \mathrm{mmol} \mathrm{L}^{-1}$ de $\mathrm{NaCl}$ em solução e obtiveram resultados que corroboram os encontrados para gliricídia.

Silva et al. (2000) e Miranda et al. (2002) também comprovaram o efeito negativo do $\mathrm{NaCl}$ no crescimento de plantas. Essa redução do crescimento das plantas submetidas a concentrações crescentes de $\mathrm{NaCl}$ em solução nutritiva deve-se a um provável efeito osmótico, associado à toxidez de íons pela absorção excessiva de $\mathrm{Na}$ e $\mathrm{Cl}$ e ao desequilíbrio nutricional causado pelos distúrbios na absorção e, ou, distribuição dos nutrientes (Munns, 2002; Lacerda, 2005), indicando baixa tolerância da espécie. Plantas tolerantes à salinidade têm a capacidade de estabelecer um equilíbrio osmótico com a baixa disponibilidade de água no solo (Lima, 1997). Isso se torna possível, provavelmente, por acumularem os íons absorvidos nos vacúolos das células foliares, mantendo a concentração salina no citoplasma e nas organelas em baixos níveis, de modo a não interferirem nos mecanismos enzimáticos e no metabolismo e, consequentemente, no crescimento.

As produções de matéria seca de folhas, caules, raízes e total (Figura 2) seguiram modelos de resposta quadráticos, com redução nos valores dessas variáveis à medida que se aumentaram as concentrações de $\mathrm{NaCl}$ na solução.

Esse comportamento também foi observado por Fernandes et al. (2002) em mudas de pupunheira
(Bactris gasipaes) e Neves et al. (2004) em umbuzeiro (Spondias tuberosa), submetidos a concentrações menores que as utilizadas no presente estudo.

A matéria seca total apresentou redução de $62 \%$, quando comparada ao tratamento sem adição de sal, na concentração de $100 \mathrm{mmol} \mathrm{L}^{-1}$ de $\mathrm{NaCl}$; a partir de $200 \mathrm{mmol} \mathrm{L}^{-1}$, essa redução atingiu $70 \%$. Esses resultados permitem inferir que a gliricídia pode ser considerada sensível ao estresse salino na dose de $100 \mathrm{mmol} \mathrm{L}^{-1}$ de $\mathrm{NaCl}$ em solução. Além da redução do crescimento, outro efeito do estresse salino que possivelmente contribuiu para redução da matéria seca das plantas foi a abscisão foliar - verificada nas plantas especialmente nos tratamentos com concentrações mais elevadas de $\mathrm{NaCl}$. Neves et al. (2004) também observaram, a partir da concentração de $100 \mathrm{mmol} \mathrm{L}^{-1}$ de $\mathrm{NaCl}$ em solução, abscisão precoce das folhas mais velhas e morte de plantas de umbuzeiro. Esse fato provavelmente está associado à toxidez de íons pela absorção excessiva de $\mathrm{Na}$ e $\mathrm{Cl}$.

Com relação aos teores de nutrientes, observou-se que com o aumento das concentrações de $\mathrm{NaCl}$ houve redução nos teores de macronutrientes nas partes da planta estudadas (Figura 3). Esse comportamento corrobora as respostas obtidas na produção de matéria seca, pois a produção está diretamente relacionada ao equilíbrio nutricional das plantas.

Os teores de N, P, K, Ca, Mg e S foram significativamente maiores nas plantas crescidas sem estresse (Figura 3), indicando possível inibição competitiva com a adição do $\mathrm{NaCl}$ na solução nutritiva $(\mathrm{Hu} \&$ Schmidhalter, 1997).

Quanto aos teores de $\mathrm{K}$ e Ca, verificou-se que a absorção foi significativamente reduzida pela aplicação
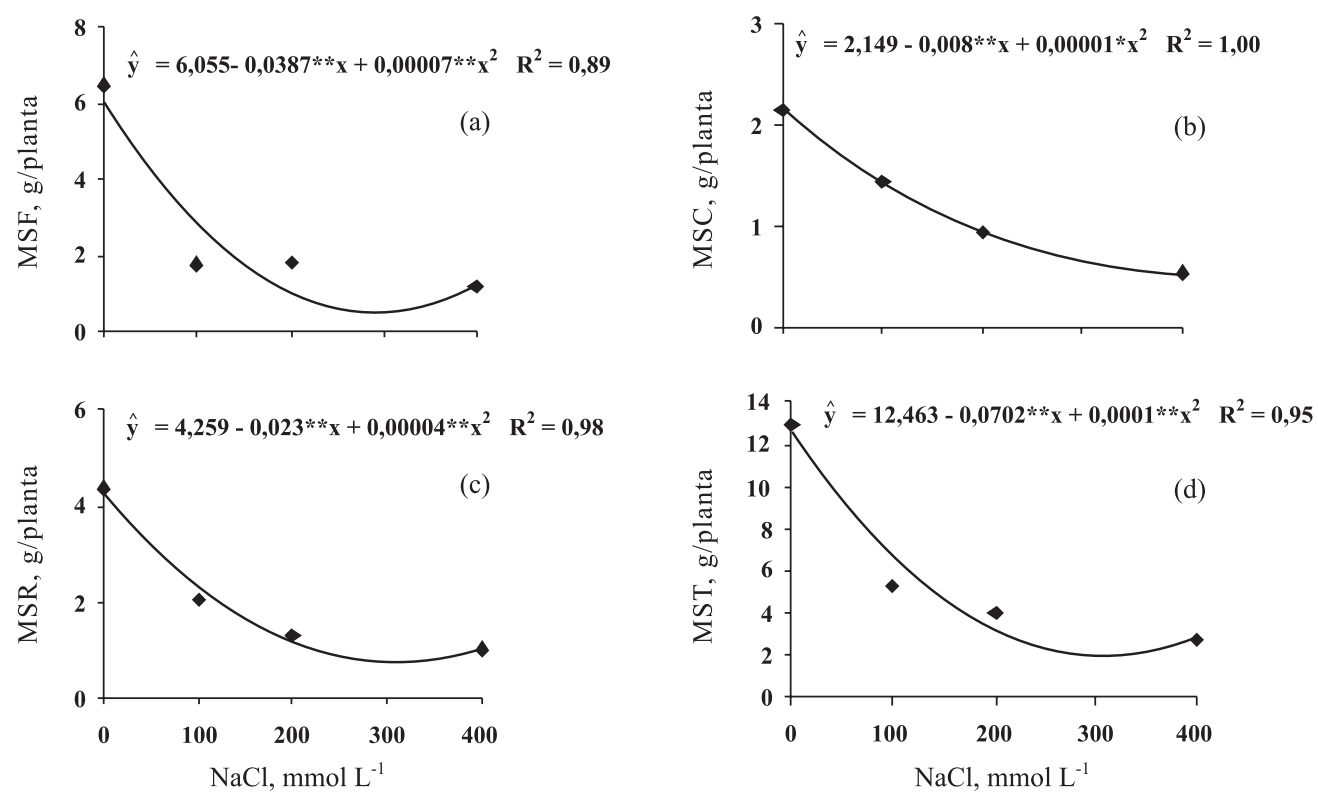

Figura 2. Incremento de matéria seca das folhas (MSF) (a), matéria seca dos caules (MSC) (b), matéria seca das raízes (MSR) (c) e matéria seca total (MST) (d) de mudas de gliricídia em função das concentrações crescentes de $\mathrm{NaCl}$ na solução nutritiva. 

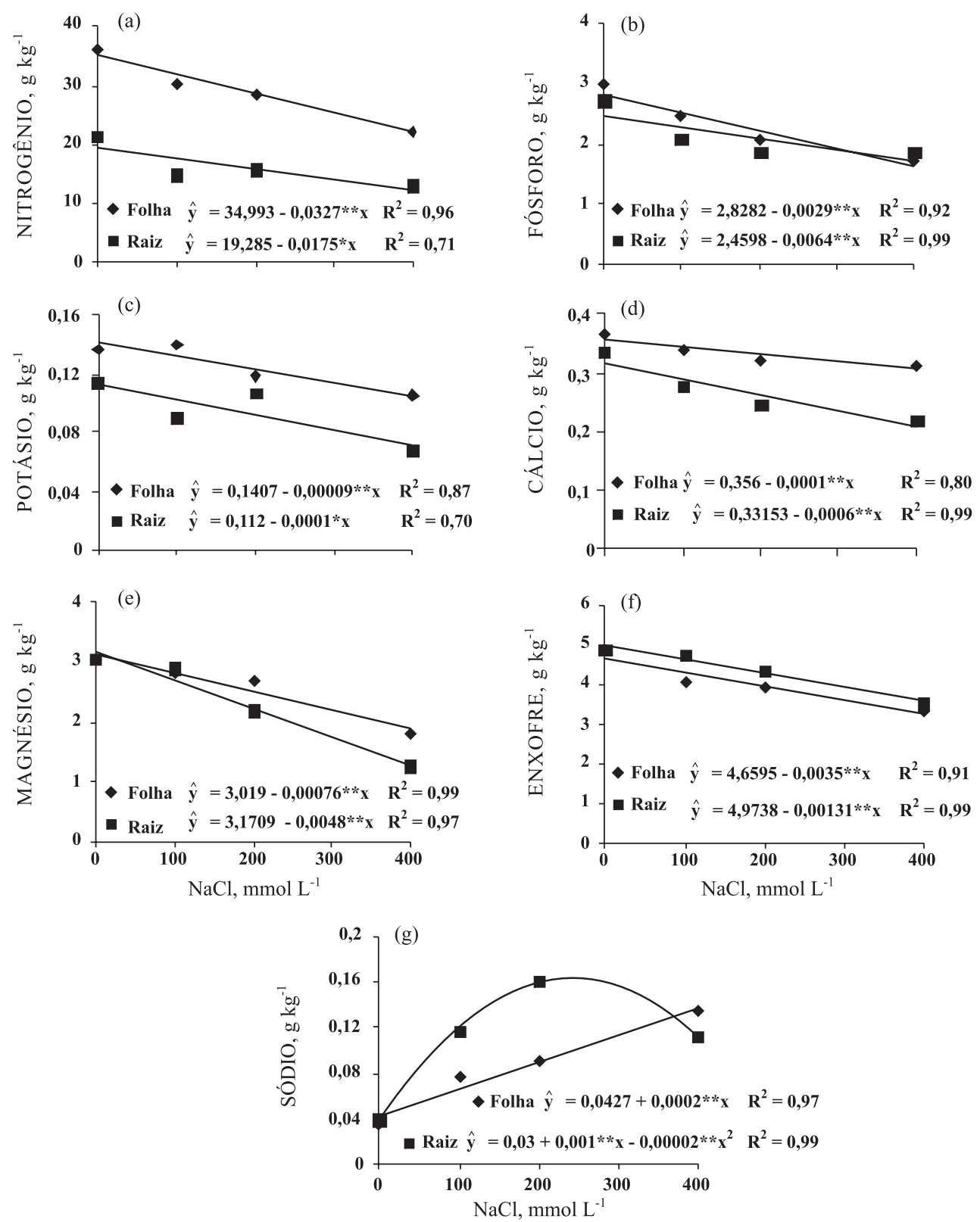

Figura 3. Teores de N, P, K, Ca, Mg, S e Na nas raízes e folhas de mudas de gliricídia em função das concentrações crescentes de $\mathrm{NaCl}$ na solução nutritiva.

de $\mathrm{NaCl}$ no meio de crescimento. Miranda et al. (2002), trabalhando com moringa (Moringa oleifera), também observaram reduções no acúmulo de $\mathrm{Ke} \mathrm{Ca}$ com o NaCl. Hu \& Schmidhalter (1997) sugeriram que, sob salinidade, a menor absorção de Ca pode permitir que o $\mathrm{Na}$ seja incorporado à estrutura da membrana plasmática, reduzindo sua seletividade e, ou, permitindo o efluxo de íons, notadamente o K.

$\mathrm{O}$ efeito do $\mathrm{NaCl}$ sobre os teores de $\mathrm{K}$ também tem sido atribuído ao antagonismo entre esses cátions (Fernandes et al., 2002). A redução na concentração de K sob estresse salino é um complicador adicional para o crescimento das plantas, visto que, em algumas situações, esse elemento é o principal nutriente a contribuir para o decréscimo do potencial osmótico.

Em relação ao $\mathrm{Ca}$, estudos têm demonstrado que o aumento da salinidade pode induzir deficiência desse nutriente. A redução na absorção de Ca pode levar à perda da integridade da membrana plasmática, com consequente perda da capacidade de absorção de alguns íons, principalmente o K (Cachorro et al., 1994).

De modo geral, os menores teores de $\mathrm{N}$ e $\mathrm{S}$ ocorreram nas maiores concentrações de $\mathrm{NaCl}$, independentemente do componente da planta considerado, devido provavelmente ao efeito depressivo da salinidade sobre a produção de matéria seca 
(Figura 2d). Esses resultados corroboram os observados por Miranda et al. (2002) em trabalhos com moringa nas concentrações de $0,30,60,90$ e $120 \mathrm{~mol} \mathrm{~m}^{-3}$ de $\mathrm{NaCl}$, nos quais se verificaram reduções no acúmulo desses nutrientes com o aumento do $\mathrm{NaCl}$.

Nas plantas-testemunha, a concentração de $\mathrm{Na}$ foi igual para os órgãos estudados (Figura 3g). No entanto, quando se adicionou $\mathrm{NaCl}$ à solução, a concentração desse elemento aumentou consideravelmente tanto na raiz como nas folhas, sendo esse efeito mais evidenciado na raiz, evitando assim sua translocação para folhas e reduzindo possíveis danos a estas. Na maior concentração de $\mathrm{NaCl}\left(400 \mathrm{mmol} \mathrm{L}^{-1}\right)$ observouse redução de $\mathrm{NaCl}$ na raiz, possivelmente devido à exclusão do elemento deletério. Aparentemente houve inibição do transporte do Na para a parte aérea, visto que suas menores concentrações foram observadas nas folhas especialmente nas concentrações de 100 e $200 \mathrm{mmol} \mathrm{L}^{-1}$ de $\mathrm{NaCl}$. Pode ter ocorrido também acúmulo nas folhas mais velhas que foram eliminadas com a abscisão foliar, fato evidenciado pela redução da matéria seca das plantas observada no presente estudo. Neves et al. (2004) observaram que concentrações de $100 \mathrm{mmol} \mathrm{L}^{-1}$ de $\mathrm{NaCl}$ em solução foram suficientes para prover abscisão precoce das folhas mais velhas e morte de plantas de umbuzeiro.

\section{CONCLUSÕES}

1. A salinidade reduziu o crescimento e a produção de matéria seca das mudas de gliricídia, indicando que esta é uma planta sensível à salinidade.

2. As concentrações crescentes de $\mathrm{NaCl}$ reduziram expressivamente os teores de N, P, K, Ca, Mg e S nas raízes e folhas de gliricídia e aumentaram os de $\mathrm{Na}$.

\section{LITERATURA CITADA}

BARBOSA, Z. Efeito do P e do Zn na nutrição e crescimento de Miracroduon urundeuva (aroeira do sertão). Lavras, Universidade Federal de Lavras, 1994. 105p. (Tese de Mestrado)

BOURSIER, P.; LYNCH, J.; LÄUCHLI, A. \& EPSTEIN, E. Chloride partioning in leaves of salt-stressed sorghum, maize, wheat and barley. Austr. J. Plant Physiol., 14:463$473,1987$.

BREMNER, J.M. \& EDWARDS, A.P. Determination and isotope ratio analysis of different forms of nitrogen in soils. I. Apparatus and procedures for destillation and determination for ammonium. Soil Sci. Soc. Am. Proc., 29:504-507, 1965.

CACHORRO, P.; OTIZ, A. \& CERDÁ, A. Implications of calcium nutrition on the response of Phaseolus vulgaris L. to salinity. Plant Soil, 159:205-212, 1994.
CARVALHO FILHO, O.M.; DRUMOND, M.A. \& LANGUIDEY, P.H. Gliricidia sepium leguminosa promissora para regiões semiáridas. Petrolina, Embrapa/CPATSA, 1997.

CHUSMAN, V. Osmoregulation in plants: Implications for agriculture. Am. Zool., 41:758-769, 2001.

CRAMER, G.R.; ALBERICO, G.J. \& SCHMIDT, C. Salt tolerance is not associated with the sodium accumulation of two maize hybrids. Austr. J. Plant Physiol., 21:675-692, 1994.

DASGAN, H.Y.; AKTAS, H.; ABAK, K. \& CAKMAK. I. Determination of screening techniques to salinity tolerance in tomatoes and investigation of genotypes responses. Plant Sci., 163:695-703, 2002.

FERNANDES, A.R.; CARVALHO, J.G.; CURI, N.; PINTO, J.E.B.P. \& GUIMARÃES, P.T.G. Nutrição mineral de mudas de pupunheira sob diferentes níveis de salinidade. Pesq. Agropec. Bras., 37:1613-1619, 2002.

FERREIRA, D.F. Análises estatísticas por meio do SISVAR (Sistema para Análise de Variância) para Windows 4.0. In: REUNIÃO ANUAL DA REGIÃO BRASILEIRA DA SOCIEDADE INTERNACIONAL DE BIOMETRIA, 45., São Carlos, 2000. Anais. São Carlos, Universidade Federal de São Carlos, 2000. p.255-258.

FOUGÈRE, F.; Le RUDULIER, D. \& STREETER, J.G. Effects of salt stress on amino acids, organic acids and carbohydrate composition of roots, bacteroids and cytosol of alfalfa (Medicago sativa L.). Plant Physiol., 96:12281236, 1991.

GONZÁLEZ-FERNÁNDEZ, J.J. \& CUARTERO, J. Evolución de la producción de cuatro entradas de tomate cultivadas con sal. Acta Hortic., 10:1067-1072, 1993.

GREENWAY, H. \& MUNNS, R. Mechanisms of salt tolerance in crop plants. Plant Physiol., 31:149-190, 1980.

HOAGLAND, D.R. \& ARNON, D.I. The water culture method of growing plants without soil. Berkeley, University of California, 1950. 32p.

HU, Y. \& SCHMIDHALTER, U. Interactive effects of salinity and macronutrient level on wheat - part II: Composition. J. Plant Nutr., 20:1169-1182, 1997.

LACERDA, C.F. Interação salinidade x nutrição mineral. In: NOGUEIRA, R.J.C.; ARAÚJO, E.L.; WILLADINO, L.G. \& CAVALCANTE, U., eds. Estresses ambientais: Danos e benefícios em plantas. Recife, Universidade Federal Rural de Pernambuco, 2005. p.127-137.

LIAO, C.F.H. Devards alloy method for total nitrogen determination. Sci. Soc. Am. J., 45:852-855, 1981.

LIMA, L.A. Efeitos de sais no solo e na planta. In: GHEYI, H.R.; QUEIROZ, J.E. \& MEDEIROS, J.F., eds. Manejo e controle da salinidade na agricultura irrigada. Campina Grande, UFPB/SBEA, 1997. p.112-136.

MALAVOLTA, E.; VITTI, G.C. \& OLIVEIRA, S.A. Avaliação do estado nutricional das plantas: Princípios e aplicações. 2.ed. Piracicaba, Associação Brasileira para Pesquisa da Potassa e do Fosfato, 1997. 319p. 
MIRANDA, J.R.P.; CARVALHO, J.G.; SANTOS, D.R.; FREIRE, A.L.O.; BERTONI, J.C.; MELO, J.R.M. \& CALDAS, A.L. Silício e cloreto de sódio na nutrição mineral e produção de matéria seca de plantas de moringa (Moringa oleifera Lam.). R. Bras. Ci. Solo, 26:957-965, 2002.

MUNNS, R. Comparative physiology of salt and water stress. Plant Cell Environ., 25:239-250, 2002.

MUNNS, R. \& TERMAAT, A. Whole plant responses to salinity. Austr. J. Plant Physiol., 13:143-160, 1986.

NEVES, O.S.C.; CARVALHO, J.G. \& RODRIGUES, C.R. Crescimento e nutrição mineral de mudas de umbuzeiro (Spondias tuberosa Arr.Cam.) submetidas a níveis de salinidade em solução nutritiva. Ci. Agrotec., 28:997-1006, 2004.
SILVA, F.A.M.; MELLONI, R.; MIRANDA, J.R.P. \& CARVALHO, J.G. Efeito do estresse salino sobre a nutrição mineral e o crescimento de mudas de aroeira (Miracroduon urundeuva) cultivadas em solução nutritiva. Cerne, 6:52-59, 2000.

SZABOLCS, I. Salt-affected soils. Washington, Library of Congress, 1989. 274p.

TYERMAN, S.D. \& SKERRETT, I.M. Root ion channels and salinity. Sci. Hortic., 78:175-235, 1999.

VINCENT, J.M. A manual for the pratical study of root-nodule bacteria. Oxford, Blackwell Scientific Publications, 1970. 200p. 